\title{
Novel Applications of Lead Acetate and Flow Cytometry Methods for Detection of Sulfur-Containing Molecules
}

\author{
Evgeniya Anishchenko ${ }^{1,2, \dagger}$, Carmela Vigorito ${ }^{1,2, \dagger}$, Luigi Mele ${ }^{3}$, Patrizia Lombari ${ }^{1,2}$, \\ Alessandra F. Perna ${ }^{1, *(1)}$ and Diego Ingrosso ${ }^{2}$ \\ 1 Department of Translational Medical Sciences, University of Campania “Luigi Vanvitelli," \\ 80131 Naplesm, Italy; anishchenkoea@gmail.com (E.A.); ca.vigorito86@libero.it (C.V.); \\ patrizia.lombari@gmail.com (P.L.) \\ 2 Department of Precision Medicine, University of Campania “Luigi Vanvitelli," 80138 Naples, Italy; \\ diego.ingrosso@unicampania.it \\ 3 Department of Experimental Medicine, University of Campania “Luigi Vanvitelli," 80138 Naples, Italy; \\ luigi.mele@unicampania.it \\ * Correspondence: alessandra.perna@unicampania.it; Tel.: +39-081-566-6822 \\ + The two authors contributed equally to the paper.
}

Received: 18 December 2018; Accepted: 29 January 2019; Published: 1 February 2019

check for updates

\begin{abstract}
Hydrogen sulfide $\left(\mathrm{H}_{2} \mathrm{~S}\right)$ is the most recently established gaseous vasodilator, enzymatically produced from cysteine metabolism, involved in a number of pathophysiological processes. However, its accurate detection in vivo is critical due to its volatility and tendency to form sulfane sulfur derivatives, thus limiting the data interpretation of its biological roles. We developed new applications of the simple and rapid method to measure $\mathrm{H}_{2} \mathrm{~S}$ release in cell culture systems, based on the lead acetate strip test. This test, previously prevalently used in microbiology, was compared with the agar trap method, applied, in parallel, on both cell cultures and cell-free samples. Sulfane sulfur represents the major species derived from intracellular $\mathrm{H}_{2} \mathrm{~S}$. Various fluorescent probes are available for quantitation of $\mathrm{H}_{2} \mathrm{~S}$ derivatives intracellularly. We present here an alternative to the classic imaging method for sulfane sulfur evaluation, running on a flow cytometer, based on SSP4 probe labeling. Flow cytometry turned out to be more direct, fully quantitative and less time-consuming compared to microscopy and more precise with respect to the fluorescence multi-plate reader assay. The new application methods for $\mathrm{H}_{2} \mathrm{~S}$ determination appear to be fully suitable for the analysis of $\mathrm{H}_{2} \mathrm{~S}$ release and sulfane sulfur content in biological samples.
\end{abstract}

Keywords: $\mathrm{H}_{2} \mathrm{~S}$; SSP4; fluorescent probe; sulfane sulfur species; lead acetate test strips; flow cytometer; fluorescence imaging; agar trap; cell culture

\section{Introduction}

Hydrogen sulfide $\left(\mathrm{H}_{2} \mathrm{~S}\right)$, previously only considered a hazardous gas, was, in the 1990s, detected in mammalian tissues and found indispensable in physiological concentrations. $\mathrm{H}_{2} \mathrm{~S}$ is biosynthesized through enzymatic reactions in human tissues, although $50 \%$ of this gas is generated by the microbiota, in the inner and outer mucus layers of the intestine [1]. In the last two decades, the metabolism and physiological roles of $\mathrm{H}_{2} \mathrm{~S}$ and its derivatives, such as the amount released from Fe-S proteins and sulfane sulfur species, have been also related to various pathological situations [2,3]. Controversies have been raised on the physiological $\mathrm{H}_{2} \mathrm{~S}$ active concentrations, which have been detected in the $10^{-5}-10^{-4}$ molar range [4,5]. Detailed study of $\mathrm{H}_{2} \mathrm{~S}$ role in metabolic processes showed its beneficial effects on neuromodulation [6], cardiovascular (CV) [7-9] and immune systems, while its impairment 
was observed in several pathologies such as renal dysfunction [3], atherosclerosis [10,11], diabetes [12] and hypertension [13].

Two major fractions of metabolically active $\mathrm{H}_{2} \mathrm{~S}$ have been characterized and are generally worth evaluating: free $\mathrm{H}_{2} \mathrm{~S}$ and sulfane sulfur [1,14-16]. Cell model systems are largely employed for studies on vasodilator gases, including $\mathrm{H}_{2} \mathrm{~S}$. In these subsets, measurements of free $\mathrm{H}_{2} \mathrm{~S}$ can be attained using the agar trap method, which is based on the methylene blue reaction [17]. Other colorimetric methods, based on reactions with silver ions [18], bismuth (III) chloride [19] and potentiometric methods [20-22], were developed to detect $\mathrm{H}_{2} \mathrm{~S}$ production. These last methods generally are time- and work-consuming procedures and/or their accuracy has been criticized. On the other hand, we were intrigued from acknowledging that the lead acetate strips test, used to detect $\mathrm{H}_{2} \mathrm{~S}$ produced by microorganisms [23] and to evaluate the quality of water and food [24,25], although declared by the producer "the more sensitive than any other method for detecting hydrogen sulfide production" [23], has never been used, for quantitating $\mathrm{H}_{2} \mathrm{~S}$ release in cell cultures, on a routine basis. We have indeed here developed a new protocol for the application of the lead acetate strip test to cell cultures.

Hydrogenous polysulfides are actual signaling molecules with even higher nucleophilicity and reducibility than $\mathrm{H}_{2} \mathrm{~S}$ [26]. The fluorescence probes for hydrogenous polysulfides achieved widespread applicability in recent studies [27-31]. Some of these probes are even organelle-specific and thus able to selectively label and allow tracing sulfur compounds in mitochondria [26,32]. Moreover, it is possible to monitor, in real-time, variations in polysulfide cell content and/or in vivo [33]. Among a vast variety of fluorescence probes, potentially able to interact with sulfur species, endogenous hydropolysulfides, $\mathrm{H}_{2} \mathrm{~S}$, etc., we chose the widely used and commercially available Sulfane Sulfur Probe 4 (SSP4).

Sulfane sulfur is a very important species, including persulfides (R-S-SH), polysulfides $\left(\mathrm{R}-\mathrm{S}_{\mathrm{n}}-\mathrm{SH}\right.$ or R-S-S $\left.\mathrm{S}_{n}-\mathrm{S}-\mathrm{R}\right)$, inorganic hydrogen polysulfides $\left(\mathrm{H}_{2} \mathrm{~S}_{\mathrm{n}}, \mathrm{n} \geq 2\right)$ and protein-bound elemental sulfur $\left(\mathrm{S}^{8}\right)$. Sulfane sulfur related species are generated following oxidation of cellular $\mathrm{H}_{2} \mathrm{~S}$ and they are thought to serve as a source of endogenously released $\mathrm{H}_{2} \mathrm{~S}[14,34]$. To measure sulfane sulfur, several specific molecular probes have been developed [35,36]. In this work, we also successfully employed cytofluorometry, coupled with molecular labeling using the last generation of SSP4, to measure sulfane sulfur production in cell cultures.

\section{Experimental Design}

\section{Molecular mechanisms involved in $\mathrm{H}_{2} \mathrm{~S}$ production and regulation}

Cystathionine- $\beta$-synthase (CBS) and Cystathionine- $\gamma$-lyase (CSE), are transsulfuration pathway enzymes, which independently catalyze $\mathrm{H}_{2} \mathrm{~S}$ production intracellularly $[37,38]$. S-adenosyl-methionine (SAM) is a powerful allosteric activator of CBS; vitamin B6 is the precursor of the pyridoxal phosphate coenzyme for both CBS and CSE. Cysteine (Cys) is the major CBS and CSE substrate for $\mathrm{H}_{2} \mathrm{~S}$ biosynthesis [38]. Aminooxyacetic acid (AOAA) and DL-propargylglycine (PAG) are CBS and CSE inhibitors, respectively, which were used to assess $\mathrm{H}_{2} \mathrm{~S}$ enzymatic production. Diallyl trisulfide (DATS) is a $\mathrm{H}_{2} \mathrm{~S}$ donor which rapidly releases $\mathrm{H}_{2} \mathrm{~S}$ in the presence of Cys or glutathione (GSH) [39]. Polysulfide compounds, such as DATS, require an excess of Cys to release $\mathrm{H}_{2} \mathrm{~S}$ in a cell-free environment [40], while DATS is able to release $\mathrm{H}_{2} \mathrm{~S}$ into the cell without an excess of Cys, due to endogenous presence of this amino acid [41]. Hence, cells treated with DATS and Cys should also increase $\mathrm{H}_{2} \mathrm{~S}$ release independently from enzymatic production. In our experiments, we also added a sample treated with enzyme inhibitors to dissect the contribution of enzymatic biosynthesis from that of chemical release.

\subsection{Detection of Released $\mathrm{H}_{2} \mathrm{~S}$ Using Agar Trap or Lead Acetate Strip Test (LAST)}

The aim of this part of the experimental design was to set the conditions for the use of the lead acetate strip test (LAST) to quantitate $\mathrm{H}_{2} \mathrm{~S}$ release from cell cultures. In this phase, indeed, LAST assays 
were performed in parallel with another well-established test usually employed to evaluate the release of $\mathrm{H}_{2} \mathrm{~S}$ in vitro. The LAST assay is based on the following reaction:

$$
\mathrm{Pb}\left(\mathrm{CH}_{3} \mathrm{COO}\right)_{2}+\mathrm{H}_{2} \mathrm{~S} \rightarrow \mathrm{PbS}+2 \mathrm{CH}_{3} \mathrm{COOH}
$$

where the formation of $\mathrm{PbS}$ as a black precipitate monitors the reaction completion.

Conversely, we use the agar trap colorimetric assay, as a reference method for $\mathrm{H}_{2} \mathrm{~S}$ detection. This method is based on the entrapping of $S^{2-}$ by reaction with zinc acetate in a gel matrix. Then, the assay detects methylene blue, formed as the result of the reaction of $S^{2-}$ released from the matrix with N,N-Dimethyl-p-phenylenediamine sulfate in the presence of $\mathrm{FeCl}_{3}$ in an acidic microenvironment.

First, we prepared the reference standard for construction of the calibration curve. To this purpose, serial dilutions of NaHS solution in the 25-200 $\mu \mathrm{M}$ range were prepared to obtain standard curves in a concentration range suitable for both methods and to compare the two methods in the concentration range of interests (Figure 1a).

Then, we performed parallel experiments using agar trap and LAST to evaluate $\mathrm{H}_{2} \mathrm{~S}$, released from cell cultures in time courses at $6 \mathrm{~h}$ and $12 \mathrm{~h}$. The $\mathrm{H}_{2} \mathrm{~S}$ evaluation was performed on five experimental groups and contained: (1) non-treated control CTRL (-); (2) stimulated control, CTRL (+): Cys, B6, and SAM; (3) inhibitors (PAG and AOAA); (4) stimulators (Cys, B6, and SAM) and inhibitors (PAG, AOAA); and (5) DATS and stimulators (Figure 1b).

Lastly, we performed a $1 \mathrm{~h}$ experiment using the agar trap method with cell-free 100 and $200 \mu \mathrm{M}$ NaHS aqueous solutions in different humidity conditions (36 and 68\%) to demonstrate the influence of the microenvironment onto the preciseness of agar trap method (Figure 1c).

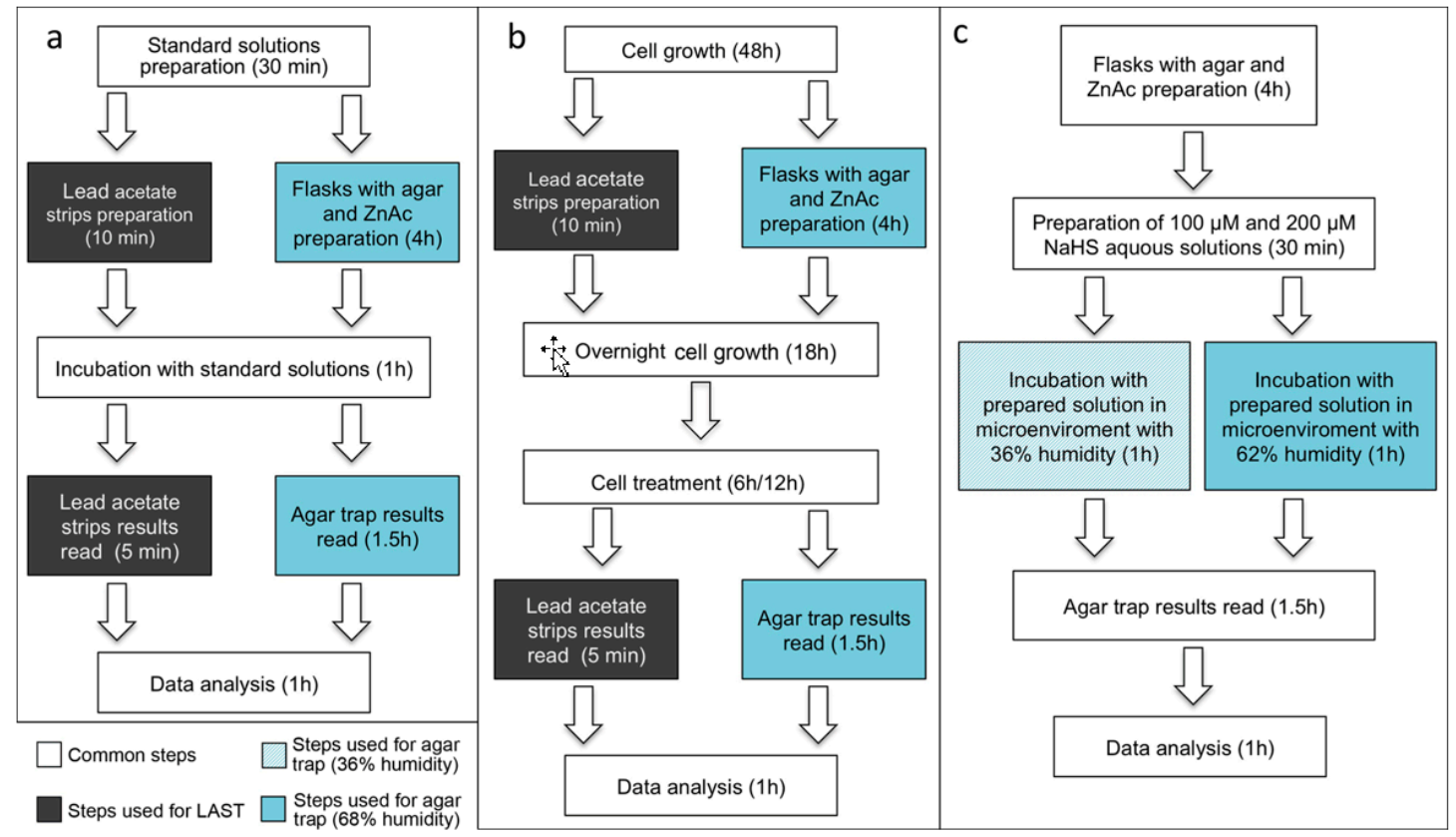

Figure 1. The scheme of experimental design for agar trap and LAST assays: (a) experimental design for standard curves; (b) scheme for experiments in cell culture; and (c) experimental design for detect levels of agar trap method precision in different microenvironmental conditions. ZnAc; zinc acetate.

\subsection{Measuring of Sulfane Sulfur Species Using SSP4 and Flow Cytometry in Comparison to Fluorescence Microscopy}

The aim of this part of the experimental design was to optimize the use of SSP4 as a fluorescence probe to quantitate sulfane sulfur intracellularly. SSP4 is a fluorescent probe of the last generation, capable of reacting with sulfane sulfur species, according to the reaction scheme in Figure $2 \mathrm{a}$, thus allowing quantitative detection with high accuracy, reproducibility and sensitivity. Fluorescence 
microscopy and spectrometry (including multi-plate readers) are the recommended techniques to detect SSP4 labeling, as suggested by the supplier's protocol. Our aim was to optimize this technique, by increasing precision and dependability of this approach. We chose flow cytometry to evaluate sulfane sulfur content in live cells using SSP4, in parallel fluorescence microscopy for comparison (Figure 2b). In addition to the experimental groups described in Section 2.1, we accomplished these experiments under various conditions. We included in the protocol cell samples treatments with glutathione (GSH) and stimulators (Cys, B6, and SAM), which are expected to increase sulfane sulfur formation. In fact, it was demonstrated that activation of CBS/CSE, in presence of GSH and Cys, generates CysSSH and CysSSSH, subsequently forming sulfane sulfur species due to sulfur transfer from CysSSH to GSH in a CBS/CSE dependent manner [42].

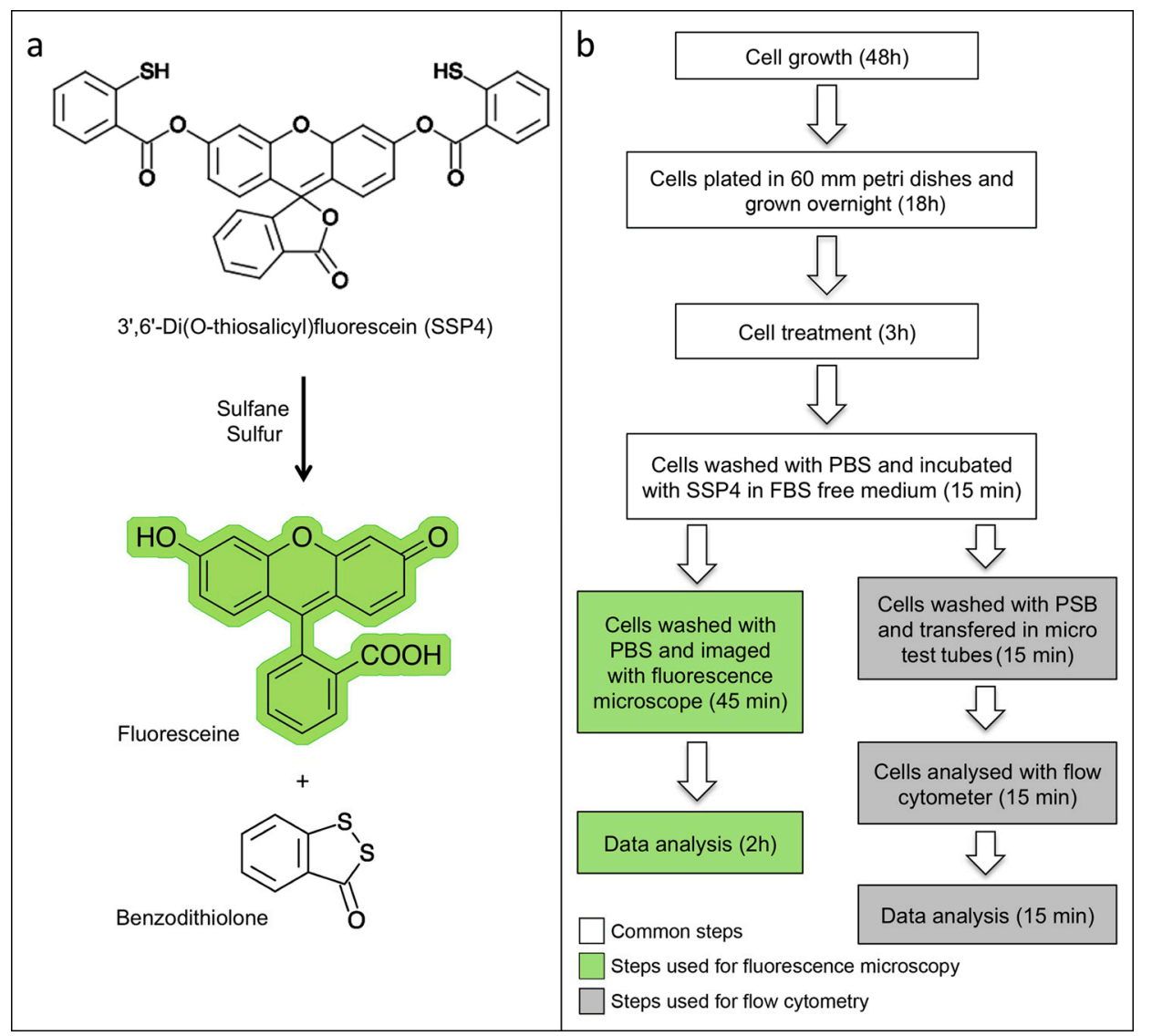

Figure 2. The principle of reaction and design of experiments with SSP4: (a) Sulfane Sulfur Probe 4 in presence of sulfane sulfur species cleaves fluorescein (shown in green) that could be detected at $\lambda_{\mathrm{ex}} 482 \mathrm{~nm}$ and $\lambda_{\mathrm{em}} 515 \mathrm{~nm}$; and (b) experimental design for detection sulfane sulfurs in cells culture with fluorescence microscope and/or flow cytometer using SSP4. PBS, Phosphate-Buffered Saline; FBS, Fetal Bovine Serum.

\subsection{Materials}

- Agar (AppliChem, Darmstadt, Germany; Cat. no.: A0949, 1000)

- Aminooxyacetic acid hemihydrochloride, AOAA (Aldrich, St.Louis, MO, USA; Cat. no.: C13408)

- Cetyltrimethylammonium bromide, CTAB (Sigma, St.Louis, MO, USA; Cat. no.: H9151)

- Diallyl trisulfide, DATS (Cayman Chemical, Ann Arbor, MI, USA; Cat. no.: 2050-87-5)

- Dimethyl sulfoxide, DMSO (Sigma-Aldrich, St.Louis, MO, USA; Cat. no.: W387520)

- $\quad$ DL-cysteine, Cys (Aldrich, St.Louis, MO, USA; Cat. no.: 861677)

- $\quad$ DL-propargylglycine, PAG (Sigma, St.Louis, MO, USA; Cat. no.: P7888)

- Dulbecco's Modified Eagle's Medium, DMEM (Sigma, St.Louis, MO, USA; Cat. no.: D4947) 
- Dulbecco's Phosphate-Buffered Saline, PBS (Microtech Srl, Pozzuoli, Italy; Cat. no.: L0615-500)

- Fetal Bovine Serum (South America), FBS (Microtech Srl, Pozzuoli, Italy; Cat. no.: S1810-500)

- Human Endothelial Somatic Cell Hybrid, EA.hy926 (American Type Culture Collection, Manassas, VA, USA; Cat. no.: CRL-2922 ${ }^{\mathrm{TM}}$ )

- Hydrochloric Acid, $\mathrm{HCl}$ (Sigma, St.Louis, MO, USA; Cat. no.: H1758)

- Iron (III) chloride, $\mathrm{FeCl}_{3}$ (Sigma-Aldrich, St.Louis, MO, USA; Cat. no.: 157740)

- Lead acetate strips test (Sigma-Aldrich, St.Louis, MO, USA; Cat. no.: 06728)

- L-glutamine (Microtech Srl, Pozzuoli, Italy; Cat. no.: X0550-100)

- $\quad$ L-glutathione reduced, GSH (Sigma, St.Louis, MO, USA; Cat. no.: G6013)

- $\quad$ N,N-dimethyl-p-phenylenediamine sulfate salt, NDPS (Aldrich, St.Louis, MO, USA; Cat. no.: 186384)

- Penicillin-streptomycin (Microtech Srl, Pozzuoli, Italy; Cat. no.: L0022-100)

- $\quad$ Pyridoxine hydrochloride, B6 (Sigma, St.Louis, MO, USA; Cat. no.: P6280)

- S-adenosyl-methionine, SAM (New England Biolabs Inc, Ipswich, MA, USA; Cat. no.: B9003S)

- Sodium hydrosulfide hydrate, NaHS (Sigma-Aldrich, St.Louis, MO, USA; Cat. no.: 161527)

- Sodium hydroxide pellets, $\mathrm{NaOH}$ (Carlo Erba, Rodano, Italy, Cat. no.: 480507)

- Sulfane Sulfur Probe 4, SSP4 (Dojindo Laboratories, Kumamoto, Japan; Cat. no.: SB10)

- Trypsin-EDTA (Microtech Srl, Pozzuoli, Italy; Cat. no.: L0940-100)

- Zinc acetate dihydrate, ZnAc (Sigma, St.Louis, MO, USA; Cat. no.: 383058-500G)

\subsection{Equipment}

- Multimode Microplate Reader “Tecan Infinite” (Tecan Group Ltd, Männedorf, Switzerland; Cat. no.: M200)

- Confocal Laser Scanning Microscope (Zeiss, Milan, Italy; Cat. no.: LSM 710)

- $\quad$ Flow cytometer Accuri ${ }^{\mathrm{TM}}$ C6 Plus (BD Biosciences, San Jose, CA, USA)

- UV/VIS Spectrophotometer Lambda 25 (Perkin Elmer, Waltham, MA, USA; Cat. no.: L6020060)

- Multifunctional InkJet printer (Brother Industries, Ltd, Nagoya, Japan, Cat. no.: DCP-197C)

- Water Jacketed Incubator Thermo Forma 3851 (Thermo Fisher Scientific, Waltham, MA, USA)

- Incubator Heraeus B6 (Kendro, Langenselbold, Germany, Cat. no.: 63505)

- Laboratory sterile hood (STERIL spa, Milan, Italy, Cat. no.: VBH 48 MP/99)

- Centrifuge (Eppendorf, Hamburg, Germany, Cat. no.: 5810 R)

\section{Procedure}

\section{Cell culture and treatments}

Grow human cell line EA.hy926 in DMEM medium with 10\% FBS, 2 mM L-glutamine and 0.1\% penicillin-streptomycin. For $\mathrm{H}_{2} \mathrm{~S}$ release detection experiments, plate cells in cell culture flasks $14 \mathrm{~h}$ before any experiment. Cell treatments include:

- 5 mM Cys, 5 mM B6, $10 \mu \mathrm{M}$ SAM;

- 2 mM GSH;

- $150 \mu \mathrm{M}$ DATS; and

- $2 \mathrm{mM}$ PAG, $2 \mathrm{mM}$ AOAA.

Cells growth conditions: $37^{\circ} \mathrm{C}$ in a humidified atmosphere with $5 \% \mathrm{CO}_{2}$.

Perform LAST and agar trap experiments, in triplicates in two biological repeats. Each sample consist of 500,000 cells in $5 \mathrm{~mL}$ of DMEM left overnight before treatment in $25 \mathrm{~mL}$ cell culture flasks. Standard treatment duration is $6 \mathrm{~h}$ and $12 \mathrm{~h}$, respectively, under the above conditions. 


\subsection{LAST in Comparison to Agar Trap Method. Time for Completion: Four Days}

\subsubsection{Agar Trap Method}

Prepare flasks for agar trap method as described before [3,17]. Flasks are laid horizontally upside-down; $5 \mathrm{~mL}$ of $1 \%$ agar with $7.23 \mathrm{mM} \mathrm{ZnAc}$ and $162 \mathrm{mM} \mathrm{NaOH}$ are allowed to polymerize on the bottom surface inside each flask. Once the agar is solidified, turn the flasks and plate cells on the bottom. Treat cells as appropriate. At the end of treatment, withdraw the medium and lay $2 \mathrm{~mL}$ of $500 \mathrm{mM} \mathrm{NaOH}, 100 \mu \mathrm{M}$ EDTA solution onto the agar gel and right after $500 \mu \mathrm{L}$ of detection solution (17.1 mM NDPS and $37 \mathrm{mM} \mathrm{FeCl}_{3}$ in $6 \mathrm{M} \mathrm{HCl}$ ) [43]. Measure color development in $15 \mathrm{~min}$ with spectrophotometer at $\lambda 668 \mathrm{~nm}$ against an agar gel blank kept with cell free DMEM (Figure 3a,d, Figures $4 \mathrm{a}$ and 5).

\subsubsection{LAST}

Standard Curve. Time for Completion: 02:45 Hours

1. Cut lead acetate strips using a paper perforator;

2. Place test strips into the internal side of each flask lid, using a double-sided adhesive tape.

3. Sterilize flask lids using UV light.

II PAUSE STEP Sterile lids can be stored at $4{ }^{\circ} \mathrm{C}$ until use for weeks.

4. For standard curve, add $3 \mathrm{~mL}$ aqueous solution containing 25, 50, 100, and $200 \mu \mathrm{M}$ NaHS to flasks and tightly close with the strip containing lids, following incubation for $1 \mathrm{~h}$ at $37^{\circ} \mathrm{C}$.

5. At the end of the experiment, place test strips on Whatman paper sheets, and scan using a multifunctional printer.

A CRITICAL STEP Scanning should be performed within $24 \mathrm{~h}$ after experiment, since, within 3-5 days after experiment, the color can fade away.

6. Image analysis is accomplished using ImageJ software (National Institutes of Health, Bethesda, MD, USA): Analyze > Measure and Analyze > Histogram. Set fixed reading slit for each series of assay measurements (see Figure $3 b, d$ ).

LAST in Cell Culture. Time for Completion: Four Days

1. Treat cell culture in flasks as described above and tight lids containing test strips. Incubate for $6 \mathrm{~h}$ and/or $12 \mathrm{~h}$ in $5 \% \mathrm{CO}_{2}$ atmosphere.

2. At the end of experiment, repeat Steps 5 and 6 as in the previous paragraph.

3. Data are analyzed with ImageJ software, using GraphPad Prism 5 for statistics (GraphPad Software, La Jolla, CA, USA) and applying Student's two-tailed $t$-test (Figure 4b). 


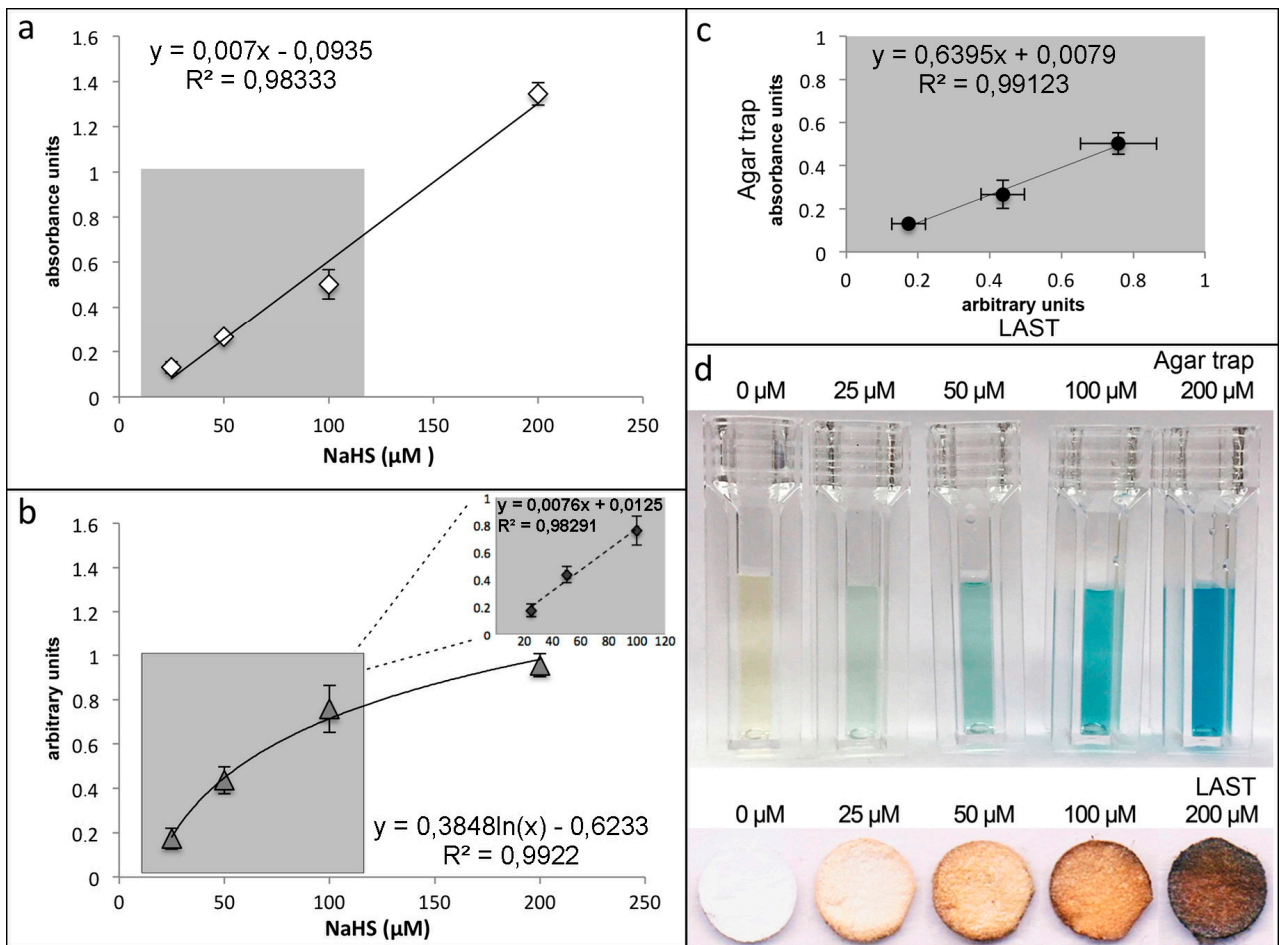

Figure 3. Comparative analysis of efficacy of agar trap and LAST: (a) calibration curve of NaHS using agar trap; (b) calibration curve of NaHS using LAST where inset (dashed line) shows the calibration curve in the 25-100 $\mu \mathrm{M}$ NaHS concentration range; (c) comparison of the NaHS calibration curves obtained using LAST ( $x$-axis) and agar trap ( $y$-axis) methods in the 25-100 $\mu \mathrm{M}$ NaHS concentrations range; and (d) both photographs show reaction products obtained of $\mathrm{H}_{2} \mathrm{~S}$, detected with agar trap developed by methylene blue staining (top), or lead acetate treated filters (bottom). LAST, lead acetate strip test.

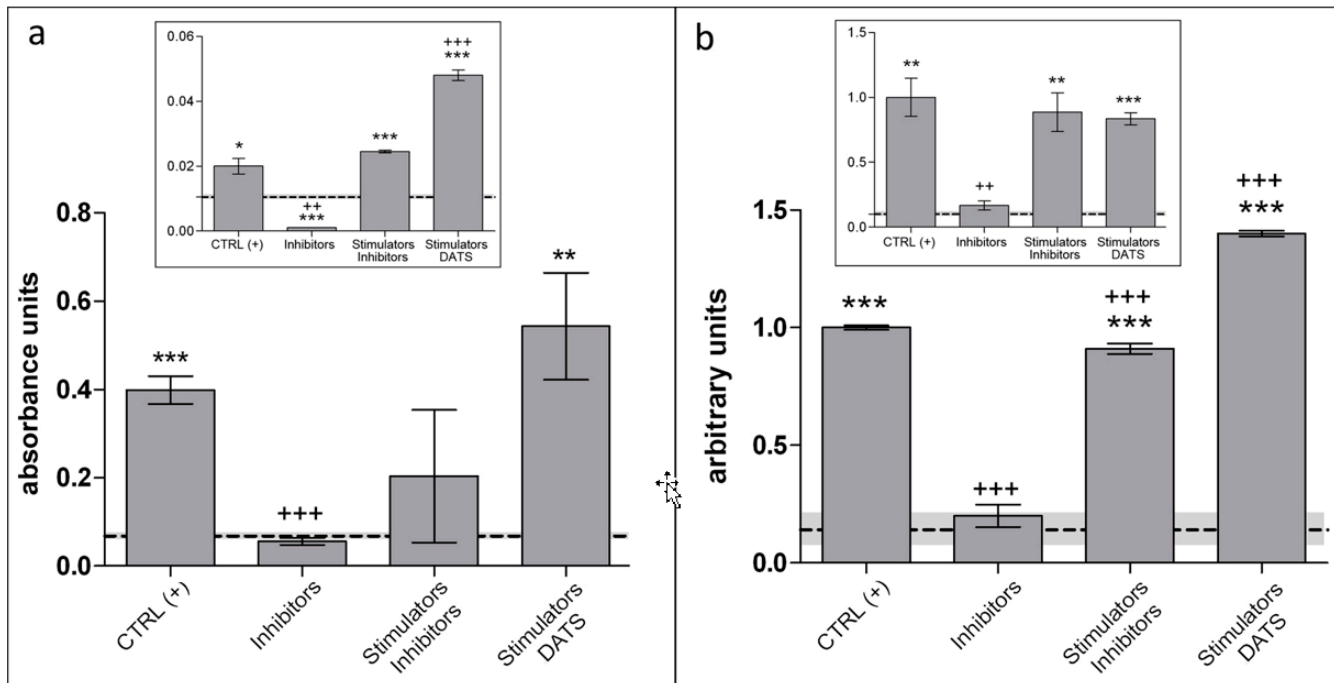

Figure 4. $\mathrm{H}_{2} \mathrm{~S}$ release in $6 \mathrm{~h}$ and $12 \mathrm{~h}$ duration assay by human endothelial cells: (a) levels of $\mathrm{H}_{2} \mathrm{~S}$ detected by agar trap method in $6 \mathrm{~h}$ and in $12 \mathrm{~h}$ (inset); and (b) levels of $\mathrm{H}_{2} \mathrm{~S}$ detected by the LAST method in $6 \mathrm{~h}$ and $12 \mathrm{~h}$ (inset). CTRL (+)/Stimulators; $5 \mathrm{mM}$ Cys, $5 \mathrm{mM}$ vitamin B6, $10 \mu \mathrm{M}$ SAM. Inhibitors; 2 mM DL-PAG and AOAA. (a,b) Samples are compared to the untreated controls CTRL (-) (indicated by the dashed baseline, SD is depicted by a gray band; data are illustrated as the mean \pm SD; $\mathrm{p}$ value versus untreated controls: ${ }^{*} p<0.05,{ }^{* *} p<0.01,{ }^{* * *} p<0.001$, while $p$ value versus CTRL (+): ${ }^{++} p<0.01,{ }^{+++} p<0.001$ (according to Student's two-tailed $t$-test). 


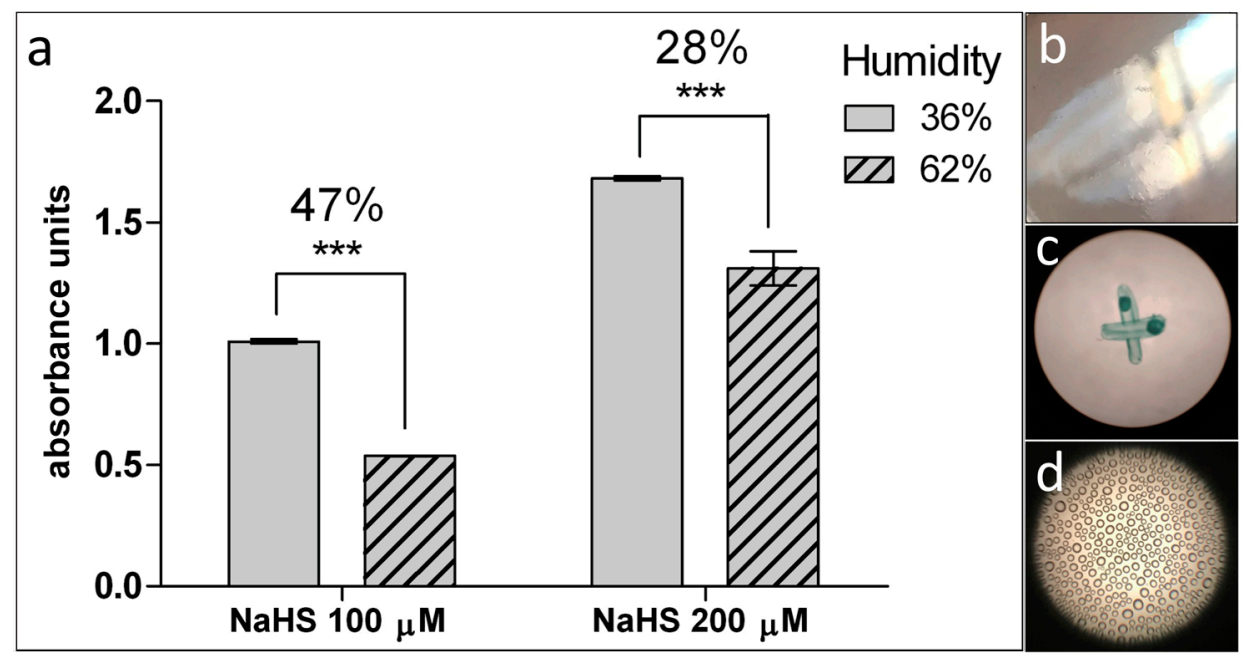

Figure 5. Effect of microenvironment humidity on the $\mathrm{H}_{2} \mathrm{~S}$ recovery in the agar trap assay. The detection of $\mathrm{H}_{2} \mathrm{~S}$ release is performed with agar trap method. (a) $\mathrm{H}_{2} \mathrm{~S}$ released from $2 \mathrm{~mL} 100$ and $200 \mu \mathrm{M}$ NaHS aqueous solution, in $1 \mathrm{~h}$ at $37^{\circ} \mathrm{C}$ by incubating in $36 \%$ or $62 \%$ humidified atmosphere. Percentage difference between samples incubated under various microenvironment conditions are indicated above each histogram. Examples of: (b) Photograph of polymerized dry agar gel before experiment; (c) microphotograph of agar gel in the sample incubated at 36\% of humidity; and (d) microphotograph of agar gel with microdrops in a sample incubated at $62 \%$ of humidity. $p$ value versus sample incubated at $36 \%$ of humidity: ${ }^{* * *} p<0.001$ (according to the Student's two-tailed $t$-test).

3.2. Sulfane Sulfur Quantitation with SSP4 Using Flow Cytometry in Comparison to Fluorescence Microscopy. Time for Completion: 00:45 Hours

Plate $60 \mathrm{~mm}$ petri dishes with 500,000 cells, in $3 \mathrm{~mL}$ of DMEM and leave overnight in incubator, before the experiment. Prepare enough dishes to perform each treatment for both fluorescence microscopy and flow cytometry in triplicate in two biological repeats, during $3 \mathrm{~h}$.

\subsubsection{Sulfane Sulfur Quantitation with SSP4 Using Fluorescence Microscopy}

Follow the general directions reported in the technical manual provided by the supplier of the SSP4 fluorescent probe [44]. Briefly, after $3 \mathrm{~h}$ treatment, wash each cell sample twice with PBS and incubate for $15 \mathrm{~min}$ in $2 \mathrm{~mL}$ of FBS-free DMEM, with $10 \mu \mathrm{M} \mathrm{SSP} 4$ and $500 \mu \mathrm{M}$ CTAB. Subsequently, wash once again and leave in PBS for imaging. SSP4-labeled cell imaging is captured using a confocal laser scanning microscope at $\lambda_{\mathrm{ex}} 482 \mathrm{~nm}$ and $\lambda_{\mathrm{em}} 515 \mathrm{~nm}$. For data analysis, employ the ImageJ software (Figure 6).

\subsubsection{Sulfane Sulfur Quantitation Using SSP4 Labelig and Detection by Flow Cytometry}

1. Treatment duration is $3 \mathrm{~h}$, then wash the cells twice with PBS and leave for $15 \mathrm{~min}$ in $2 \mathrm{~mL}$ of FBS-free DMEM with $1.5 \mu \mathrm{M}$ SSP 4 and $150 \mu \mathrm{M}$ CTAB.

2. Wash twice again with PBS and leave for $3 \mathrm{~min}$ in the presence of $0.5 \mathrm{~mL}$ Trypsin-EDTA at $37^{\circ} \mathrm{C}$.

3. Transfer detached cell samples in $1.5 \mathrm{~mL}$ micro test tubes and wash once again with PBS.

A CRITICAL STEP The subsequent analysis should be performed within 5-15 min.

4. Detect SSP4-emitted fluorescence using a flow cytometer (Accuri ${ }^{\mathrm{TM}}$ C6 Plus).

5. Analyze data using Accuri ${ }^{\mathrm{TM}}$ C6 Plus and GraphPad Prism 5 software (Figure 7). 


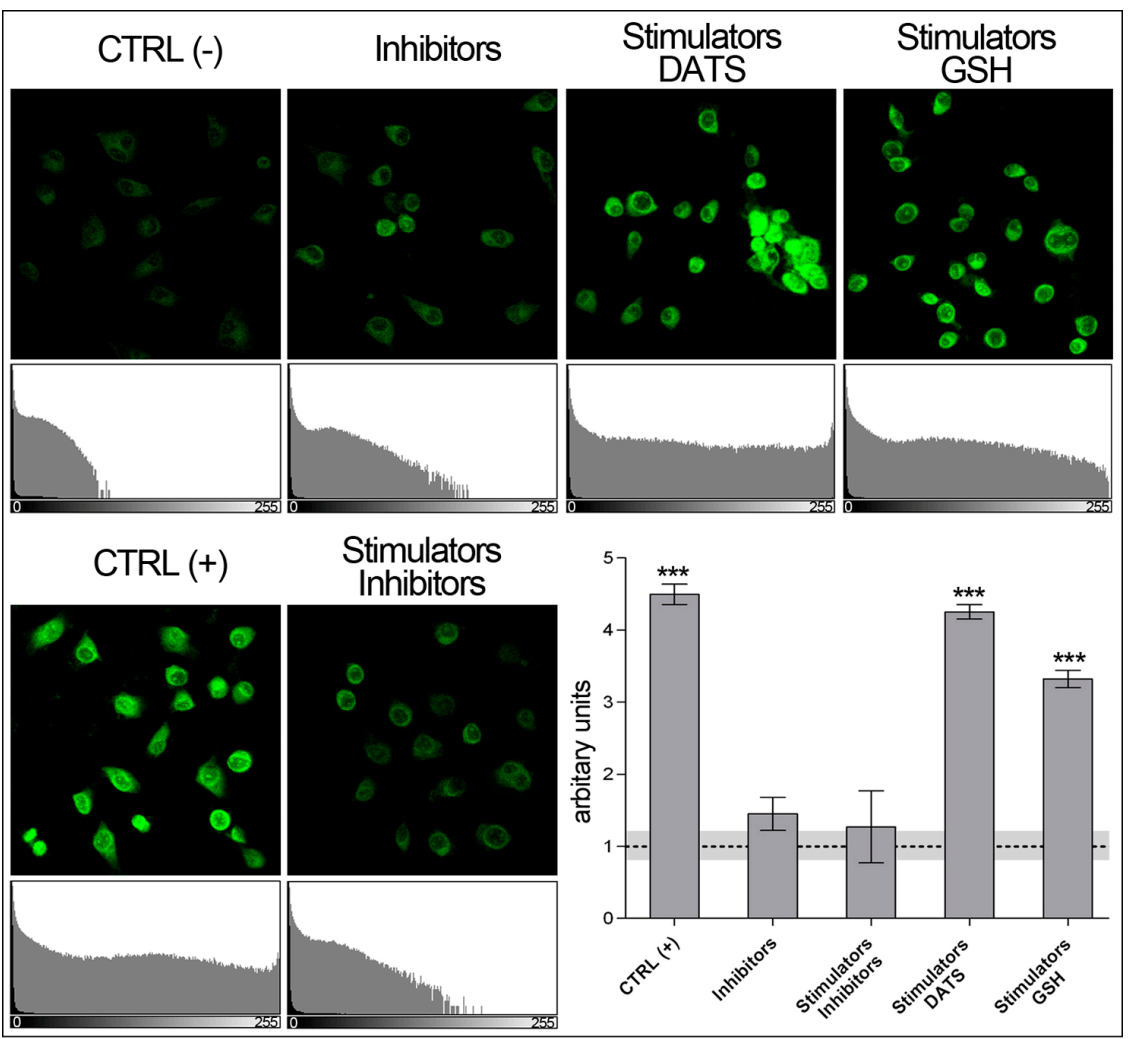

Figure 6. Detection of sulfane sulfur species using fluorescence microscope. Microphotographs of endothelial cells and corresponding histograms (below each microphotograph) show different sulfane sulfur-related fluorescence intensity, emitted by SSP4, in $3 \mathrm{~h}$, with various treatments. Images analysis performed using ImageJ software and represented using arbitrary units (lower left diagram in each panel). Untreated control, CTRL (-), in diagram is indicated as dashed baseline; gray band is the relevant $\mathrm{SD}$. Data depicted as the mean $\pm \mathrm{SD} ; \mathrm{p}$ value versus the untreated control: ${ }^{* *} p<0.01,{ }^{* * *} p<0.001$ (according to Student's two-tailed $t$-test). CTRL (+)/Stimulators; $5 \mathrm{mM} \mathrm{Cys,} 5 \mathrm{mM}$ vitamin B6, $10 \mu \mathrm{M}$ SAM. Inhibitors; 2 mM DL-PAG and AOAA.

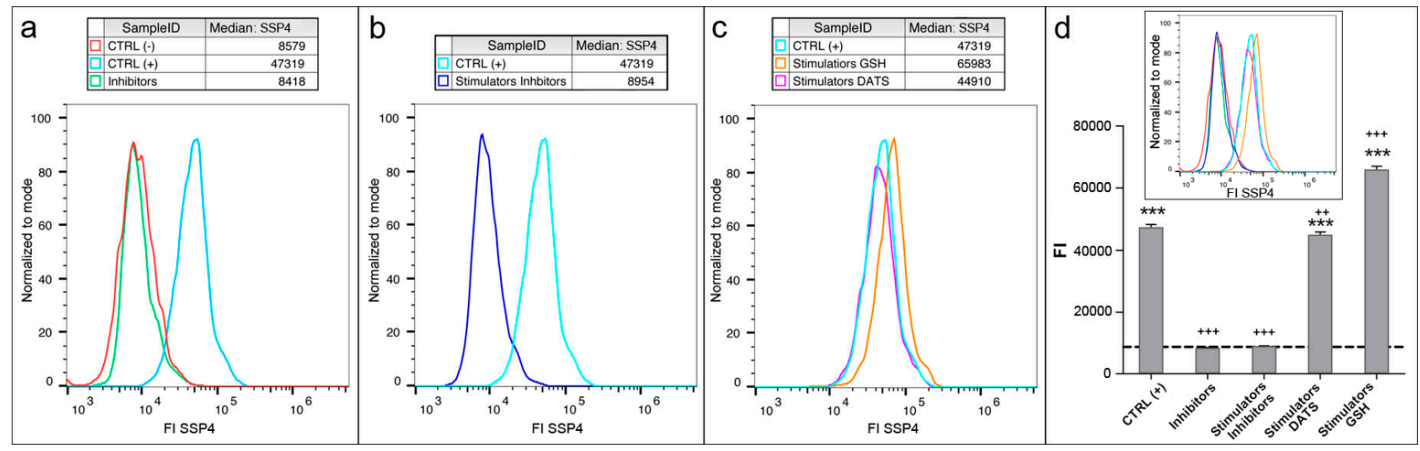

Figure 7. Detection of sulfane sulfur species using flow cytometry: $(\mathbf{a}-\mathbf{c})$ Spectrum of SSP4 fluorescence intensity, emitted in presence of sulfane sulfurs, in endothelial cells treated for $3 \mathrm{~h}$. (d) FI median values are drawn in the histogram plot, where untreated control, CTRL (-), is indicated as a dashed baseline. (d) Inset is a merge of graphs in $(\mathbf{a}-\mathbf{c})$ to allow easier comparison of the relevant data. Data are depicted as mean $\pm \mathrm{SD} ; p$ value versus untreated control: ${ }^{* * *} p<0.001$, while $p$ value versus CTRL $(+):{ }^{++} p<0.01,{ }^{+++} p<0.001$ (according to Student's two-tailed $t$-test). CTRL (+)/Stimulators; $5 \mathrm{mM}$ Cys, 5 mM vitamin B6, $10 \mu \mathrm{M}$ SAM. Inhibitors; 2 mM DL-PAG and AOAA. FI; fluorescence intensity. Color code is the same in $(\mathbf{a}-\mathbf{c})$ and the inset of $(\mathbf{d})$. 


\section{Expected Results}

The lead acetate strip test was successfully adapted to quantify $\mathrm{H}_{2} \mathrm{~S}$ release in cell culture and, compared with agar trap, was equally sensitive, during the first hour of incubation. Standard curves, for the agar trap and LAST methods, showed linear or exponential dependence of the amount of $\mathrm{H}_{2} \mathrm{~S}$ released as a function of NaHS concentration (Figure 3a,b, respectively). The sensitivity of the two methods appeared comparable. In these experiments, NaHS, used as $\mathrm{H}_{2} \mathrm{~S}$ donor, was dissolved in an aqueous solution and, hence, released as $\mathrm{H}_{2} \mathrm{~S}$ is measured.

The estimated detection linear range for gaseous $\mathrm{H}_{2} \mathrm{~S}$, released in $1 \mathrm{~h}$ at $37^{\circ} \mathrm{C}$ from an aqueous solution of NaHS, using LAST method falls within 3-3.5 $\mu \mathrm{g}$ and $56 \mu \mathrm{g}$ of NaHS. In terms of concentration, this corresponds, in good approximation, to $10 \div 200 \mu \mathrm{M}$ NaHS initially dissolved in aqueous solutions. For LAST, we used $4 \mathrm{~mm} \varnothing$ lead acetate treated filters. Thus, the minimal amount of sulfur containing solute to be detected was $0.28 \mu \mathrm{g}$ to be absorbed onto $1 \mathrm{~mm}^{2}$ filter surface. Saturation was reached at $4.5 \mu \mathrm{g} / \mathrm{mm}^{2}$. Agar trap method displays similar performances compared to LAST with respect to the lower threshold sensitivity level. Conversely, saturation was reached at lower NaHS amount (about $45 \mu \mathrm{g}$ ), corresponding to $160 \mu \mathrm{M} \mathrm{NaHS}$ in solution. We figured out that sensitivity of LAST and agar trap methods could be further increased by $25 \%$, by reducing surface area of the lead acetate filter and by reducing gel surface, thus optimizing detection solution volume, respectively.

On the other hand, according to Sitdikova and coworkers [45], a strict relationship exists between the initial NaHS concentration and that of $\mathrm{H}_{2} \mathrm{~S}$ released from the NaHS donor, by plotting the NaHS donor vs. the $\mathrm{H}_{2} \mathrm{~S}$ currently measured with an anion selective electrode. According to this extrapolation, it was possible to indirectly evaluate $\mathrm{H}_{2} \mathrm{~S}$ by multiplying $\mathrm{NaHS}$ concentration for a 0.4 factor. Applying this algorithm, the relationship of $\mathrm{H}_{2} \mathrm{~S}$ concentrations derived from $\mathrm{NaHS}$ donor was linear for both agar trap and LAST methods, up to about $40 \mu \mathrm{M} \mathrm{H}_{2} \mathrm{~S}$, corresponding to $100 \mu \mathrm{M} \mathrm{NaHS}$. The established range of linear dependence is suitable for experiments with cell cultures. In fact, in previous work, our research group observed maximal $\mathrm{H}_{2} \mathrm{~S}$ release from stimulated hepatocarcinoma cells (HepG2) in the 30-50 $\mu \mathrm{M}$ range [3]. Standard curves resulting from NaHS were reproducible and linear, $\mathrm{R}^{2}=0.99$ (Figure 3c), which allowed us to proceed with LAST analysis in cell culture.

The following analysis of $\mathrm{H}_{2} \mathrm{~S}$ release from cell culture showed consistent results for agar trap and LAST methods within $6 \mathrm{~h}$ of the various cell treatments (see Figure 4). In both experiments, CTRL $(+)$ and DATS with stimulators in cell culture significantly increased the amount of released $\mathrm{H}_{2} \mathrm{~S}$ in comparison to intact samples (dashed line) or in presence of CBS/CSE inhibitors. However, the LAST method resulted in a more precise and less dispersed data, after statistical analysis.

Importantly, agar trap method seemed to diminish its sensitivity in experiments lasting longer than $6 \mathrm{~h}$. We noticed 10-fold lower absorbance unit range in the $12 \mathrm{~h}$ experiment (inset in Figure $4 \mathrm{a}$ ) in comparison to the experiment with $6 \mathrm{~h}$ incubation (Figure 4a). LAST and agar trap showed quite different results after longer cell exposures ( $12 \mathrm{~h}$, insets in Figure 4$)$. Noteworthy, the ratio of $\mathrm{H}_{2} \mathrm{~S}$ levels, among samples detected by agar trap in $12 \mathrm{~h}$, remained similar to that detected after $6 \mathrm{~h}$ (Figure $4 \mathrm{a}$ and inset in Figure $4 \mathrm{a}$, respectively). DATS is a $\mathrm{H}_{2} \mathrm{~S}$ donor that could induce saturation, while stimulators maintained CBS/CSE activity for much longer. Thus, levels of $\mathrm{H}_{2} \mathrm{~S}$ released within $12 \mathrm{~h}$ in CTRL $(+)$ and in DATS with stimulators become very similar, according to LAST (inset in Figure $4 \mathrm{~b}$ ), as opposed to results obtained with the agar trap method (inset in Figure 2a). We hypothesize that LAST, although capable of providing a result in a shorter incubation time, is also more suitable than the agar trap method to quantitate $\mathrm{H}_{2} \mathrm{~S}$ release in long-lasting experiments (over $6 \mathrm{~h}$ ), in that it does not appear to reach saturation within this time range. As shown in Figure 5a, the percentage of humidity significantly ( $\geq 28 \%$ ) altered the agar trap sensitivity. It was noticed that agar layer in the flask with cell culture, in the $\mathrm{CO}_{2}$ incubator, became covered with condensation drops (Figure $5 \mathrm{~d}$ ). This did not occur in a lower humidity microenvironment (Figure 5c). Thus, the LAST method appears to be superior with respect to the agar trap, to measure $\mathrm{H}_{2} \mathrm{~S}$ release from cell cultures, in that it insures: 
(a) higher stability over time; (b) less tendency to saturation of the detection system; and (c) does not appear to be crucially influenced by a high degree of humidity in the chamber.

Both agar trap and LAST allow the detection of the total quantity of $\mathrm{H}_{2} \mathrm{~S}$ released over time, during cell incubation in contrast to ultra-sensitive methods such as pre-column derivatization with monobromobimane and HPLC analysis (MBB/HPLC), able to detect $\mathrm{H}_{2} \mathrm{~S}$ at nanomolar levels. For example, MBB/HPLC is a destructive method and does not allow the recovery of $\mathrm{H}_{2} \mathrm{~S}$ extracted and entrapped in a filter throughout the duration of the experiment. We may say that the two methods are complementary, in the sense that LAST may provide a "rule of thumb" best approximation of $\mathrm{H}_{2} \mathrm{~S}$ total release during incubation. Conversely, other more sensitive methods are suitable to detect end-point fine-tuned $\mathrm{H}_{2} \mathrm{~S}$ release, provided that incubation time and experimental conditions are suitable to prevent massive evaporation of $\mathrm{H}_{2} \mathrm{~S}$, or other ways to entrap this gas are employed.

Moreover, LAST does not need any special laboratory preparation or equipment. It is rapid, and cell samples are not consumed in the assay and can be recovered and used for further determination. The optimal range of released $\mathrm{H}_{2} \mathrm{~S}$ that can be detected by LAST assay corresponds to $\mathrm{H}_{2} \mathrm{~S}$ physiological concentrations found in mammals $[4,5]$.

The common methods to quantify sulfane sulfur derivatives, employing fluorescent probes, are accomplished by fluorescence microscope imaging $[35,42,46]$ or fluorescence spectrometry [14,36,42,47-50]. Fluorescence microscopy may achieve fully quantitative performances, by measuring fluorescence intensity (FI) using ImageJ or similar software. The spectrofluorometer (or multi-plate reader) also allows evaluating FI quantitatively, but this is performed on an approximate cell count based on the assumption of cell confluence in a certain plate surface. Sulfane sulfur detection, performed according to user's manual supplied with SSP4, requires spectrofluorometer or multi-plate reader. Following the original protocol, we noticed the high divergence in quantity of cells which were lost during procedures. The alterations of cells adhesion and consequently their loss after washing procedures can be due to $\mathrm{CTAB}$, a cationic surfactant hampering cell adhesion [51]. CTAB however is needed to transport SSP4 into the cells. We improved the original protocol, by reducing both SSP4 concentrations used, along with cytotoxic CTAB concentrations, the latter from 500 to $150 \mu \mathrm{M}$. These changes result in a more stable cell count during FI detection, which significantly increases reliability of results.

Flow cytometry allows exact quantitation of FI on a single cell basis and is considered to be superior, by accuracy, compared to FI evaluation by confocal microscopy or multi-plate reader analysis. In fact, the data obtained using confocal microscope (Figure 6) and using flow cytometer (Figure 7) display some crucial differences:

(a) The data obtained with flow cytometer are much more precise: the quantity of reads is identical for each sample (3000 reads), resulting in a negligible SD, indeed.

(b) The quantity of sulfane sulfurs in cells treated with GSH plus stimulators is over $20 \%$ higher than that detected in stimulated controls, CTRL $(+)$, while no significant difference can be detected by microscopy.

Author Contributions: Conceptualization, A.F.P and D.I.; Data curation, C.V., L.M. and P.L.; Formal analysis, E.A., C.V. and P.L.; Investigation, E.A. and C.V.; Methodology, E.A. and C.V.; Project administration, A.F.P.; Resources, A.F.P.; Software, E.A., C.V. and L.M.; Supervision, A.F.P and D.I.; Validation, E.A.; Visualization, E.A.; Writing-original draft, E.A. and C.V.; and Writing-review and editing, A.F.P and D.I.

Funding: Post-doctoral fellowship of Evgeniya Anishchenko was supported by a grant from Gnosis S.p.A. Carmela Vigoritos' PhD fellowship was supported by University of Campania "Luigi Vanvitelli".

Conflicts of Interest: The authors declare no conflict of interest. The funders had no role in the design of the study; in the collection, analyses, or interpretation of data; in the writing of the manuscript, or in the decision to publish the results. 


\section{References}

1. Perna, A.F.; Glorieux, G.; Zacchia, M.; Trepiccione, F.; Capolongo, G.; Vigorito, C.; Anishchenko, E.; Ingrosso, D. The role of the intestinal microbiota in uremic solute accumulation: A focus on sulfur compounds. JNEP 2019, in press. [CrossRef] [PubMed]

2. Perna, A.; Anishchenko, E.; Vigorito, C.; Zacchia, M.; Trepiccione, F.; D'Aniello, S.; Ingrosso, D. Zebrafish, a Novel Model System to Study Uremic Toxins: The Case for the Sulfur Amino Acid Lanthionine. Int. J. Mol. Sci. 2018, 19, 1323. [CrossRef] [PubMed]

3. Perna, A.F.; Di Nunzio, A.; Amoresano, A.; Pane, F.; Fontanarosa, C.; Pucci, P.; Vigorito, C.; Cirillo, G.; Zacchia, M.; Trepiccione, F.; et al. Divergent behavior of hydrogen sulfide pools and of the sulfur metabolite lanthionine, a novel uremic toxin, in dialysis patients. Biochimie 2016, 126, 97-107. [CrossRef] [PubMed]

4. Goodwin, L.R.; Francom, D.; Dieken, F.P.; Taylor, J.D.; Warenycia, M.W.; Reiffenstein, R.J.; Dowling, G. Determination of sulfide in brain tissue by gas dialysis/ion chromatography: Postmortem studies and two case reports. J. Anal. Toxicol. 1989, 13, 105-109. [CrossRef] [PubMed]

5. Warenycia, M.W.; Goodwin, L.R.; Benishin, C.G.; Reiffenstein, R.J.; Francom, D.M.; Taylor, J.D.; Dieken, F.P. Acute hydrogen sulfide poisoning. Demonstration of selective uptake of sulfide by the brainstem by measurement of brain sulfide levels. Biochem. Pharmacol. 1989, 38, 973-981. [CrossRef]

6. Qu, K.; Lee, S.W.; Bian, J.S.; Low, C.-M.; Wong, P.T.-H. Hydrogen sulfide: Neurochemistry and neurobiology. Neurochem. Int. 2008, 52, 155-165. [CrossRef]

7. Szabó, C. Hydrogen sulphide and its therapeutic potential. Nat. Rev. Drug Discov. 2007, 6, 917-935. [CrossRef]

8. Yang, G.; Wu, L.; Jiang, B.; Yang, W.; Qi, J.; Cao, K.; Meng, Q.; Mustafa, A.K.; Mu, W.; Zhang, S.; et al. H2S as a Physiologic Vasorelaxant: Hypertension in Mice with Deletion of Cystathionine-Lyase. Science 2008, 322, 587-590. [CrossRef]

9. Vandiver, M.S.; Snyder, S.H. Hydrogen sulfide: A gasotransmitter of clinical relevance. J. Mol. Med. 2012, 90, 255-263. [CrossRef]

10. Wang, X.-H.; Wang, F.; You, S.-J.; Cao, Y.-J.; Cao, L.-D.; Han, Q.; Liu, C.-F.; Hu, L.-F. Dysregulation of cystathionine $\gamma$-lyase (CSE)/hydrogen sulfide pathway contributes to ox-LDL-induced inflammation in macrophage. Cell. Signal. 2013, 25, 2255-2262. [CrossRef]

11. Zhang, H.; Guo, C.; Wu, D.; Zhang, A.; Gu, T.; Wang, L.; Wang, C. Hydrogen sulfide inhibits the development of atherosclerosis with suppressing CX3CR1 and CX3CL1 expression. PLoS ONE 2012, 7, e41147. [CrossRef] [PubMed]

12. Qian, L.-L.; Liu, X.-Y.; Chai, Q.; Wang, R.-X. Hydrogen Sulfide in Diabetic Complications: Focus on Molecular Mechanisms. Endocr. Metab. Immune Disord. Drug Targets 2018, 18, 470-476. [CrossRef] [PubMed]

13. Szijártó, I.A.; Markó, L.; Filipovic, M.R.; Miljkovic, J.L.; Tabeling, C.; Tsvetkov, D.; Wang, N.; Rabelo, L.A.; Witzenrath, M.; Diedrich, A.; et al. Cystathionine $\gamma$-Lyase-Produced Hydrogen Sulfide Controls Endothelial NO Bioavailability and Blood Pressure. Hypertension 2018, 71, 1210-1217. [CrossRef]

14. Bibli, S.-I.; Luck, B.; Zukunft, S.; Wittig, J.; Chen, W.; Xian, M.; Papapetropoulos, A.; Hu, J.; Fleming, I. A selective and sensitive method for quantification of endogenous polysulfide production in biological samples. Redox Biol. 2018, 18, 295-304. [CrossRef] [PubMed]

15. Liu, C.; Zhang, F.; Munske, G.; Zhang, H.; Xian, M. Isotope dilution mass spectrometry for the quantification of sulfane sulfurs. Free Radic. Biol. Med. 2014, 76, 200-207. [CrossRef]

16. Kabil, O.; Vitvitsky, V.; Xie, P.; Banerjee, R. The quantitative significance of the transsulfuration enzymes for H2S production in murine tissues. Antioxid. Redox Signal. 2011, 15, 363-372. [CrossRef]

17. Kartha, R.V.; Zhou, J.; Hovde, L.B.; Cheung, B.W.Y.; Schröder, H. Enhanced detection of hydrogen sulfide generated in cell culture using an agar trap method. Anal. Biochem. 2012, 423, 102-108. [CrossRef]

18. Jarosz, A.P.; Yep, T.; Mutus, B. Microplate-based colorimetric detection of free hydrogen sulfide. Anal. Chem. 2013, 85, 3638-3643. [CrossRef]

19. Yoshida, A.; Yoshimura, M.; Ohara, N.; Yoshimura, S.; Nagashima, S.; Takehara, T.; Nakayama, K. Hydrogen sulfide production from cysteine and homocysteine by periodontal and oral bacteria. J. Periodontol. 2009, 80, 1845-1851. [CrossRef] 
20. Velázquez-Moyado, J.A.; Navarrete, A. The detection and quantification, in vivo and in real time, of hydrogen sulfide in ethanol-induced lesions in rat stomachs using an ion sensitive electrode. J. Pharmacol. Toxicol. Methods 2018, 89, 54-58. [CrossRef]

21. Nagy, P.; Pálinkás, Z.; Nagy, A.; Budai, B.; Tóth, I.; Vasas, A. Chemical aspects of hydrogen sulfide measurements in physiological samples. Biochim. Biophys. Acta 2014, 1840, 876-891. [CrossRef] [PubMed]

22. Whiteman, M.; Le Trionnaire, S.; Chopra, M.; Fox, B.; Whatmore, J. Emerging role of hydrogen sulfide in health and disease: Critical appraisal of biomarkers and pharmacological tools. Clin. Sci. 2011, 121, 459-488. [CrossRef]

23. Hydrogen Sulfide Test Strips 06728. Available online: https://www.sigmaaldrich.com/catalog/product/ sial/06728 (accessed on 1 November 2018).

24. Lead Acetate Test Paper-Precision Laboratories. Available online: https://preclaboratories.com/product/ lead-acetate-test-paper/ (accessed on 1 November 2018).

25. Sulfite Test Analytical Strips Vial 10-500 PPM. Available online: https://www.bartovation.com/waterquality/sulfite-test-analytical-strips-vial-10-500-ppm (accessed on 1 November 2018).

26. Han, L.; Shi, R.; Xin, C.; Ci, Q.; Ge, J.; Liu, J.; Wu, Q.; Zhang, C.; Li, L.; Huang, W. Mitochondrial Specific H2Sn Fluorogenic Probe for Live Cell Imaging by Rational Utilization of a Dual-Functional-Photocage Group. ACS Sens. 2018, 3, 1622-1626. [CrossRef] [PubMed]

27. Gao, M.; Wang, R.; Yu, F.; Chen, L. Evaluation of sulfane sulfur bioeffects via a mitochondria-targeting selenium-containing near-infrared fluorescent probe. Biomaterials 2018, 160, 1-14. [CrossRef]

28. Han, X.; Song, X.; Li, B.; Yu, F.; Chen, L. A near-infrared fluorescent probe for sensitive detection and imaging of sulfane sulfur in living cells and in vivo. Biomater. Sci. 2018, 6, 672-682. [CrossRef] [PubMed]

29. Takano, M.; Echizen, M.; Hanaoka, K. Fluorescent probes and selective inhibitors for biological studies of H2S- and polysulfide-mediated signaling. Antioxid. Redox Signal. 2017, 27, 669-683. [CrossRef]

30. Chen, W.; Rosser, E.; Matsunaga, T.; Pacheco, A.; Akaike, T.; Xian, M. The Development of Fluorescent Probes for Visualizing Intracellular Hydrogen Polysulfides. Angew. Chem. Int. Ed. 2015, 127, 14167-14171. [CrossRef]

31. Yu, F.; Gao, M.; Li, M.; Chen, L. A dual response near-infrared fluorescent probe for hydrogen polysulfides and superoxide anion detection in cells and in vivo. Biomaterials 2015, 63, 93-101. [CrossRef]

32. Huang, Y.; Yu, F.; Wang, J.; Chen, L. Near-Infrared Fluorescence Probe for in Situ Detection of Superoxide Anion and Hydrogen Polysulfides in Mitochondrial Oxidative Stress. Anal. Chem. 2016, 88, 4122-4129. [CrossRef]

33. Umezawa, K.; Kamiya, M.; Urano, Y. A Reversible Fluorescent Probe for Real-Time Live-Cell Imaging and Quantification of Endogenous Hydropolysulfides. Angew. Chem. Int. Ed. 2018, 57, 9346-9350. [CrossRef]

34. Du, Z.; Song, B.; Zhang, W.; Duan, C.; Wang, Y.-L.; Liu, C.; Zhang, R.; Yuan, J. Quantitative Monitoring and Visualization of Hydrogen Sulfide in Vivo Using a Luminescent Probe Based on a Ruthenium(II) Complex. Angew. Chem. Int. Ed. Engl. 2018, 57, 3999-4004. [CrossRef] [PubMed]

35. Chen, W.; Liu, C.; Peng, B.; Zhao, Y.; Pacheco, A.; Xian, M. New fluorescent probes for sulfane sulfurs and the application in bioimaging. Chem. Sci. 2013, 4, 2892-2896. [CrossRef] [PubMed]

36. Takano, Y.; Hanaoka, K.; Shimamoto, K.; Miyamoto, R.; Komatsu, T.; Ueno, T.; Terai, T.; Kimura, H.; Nagano, T.; Urano, Y. Development of a reversible fluorescent probe for reactive sulfur species, sulfane sulfur, and its biological application. Chem. Commun. 2017, 53, 1064-1067.

37. Chiku, T.; Padovani, D.; Zhu, W.; Singh, S.; Vitvitsky, V.; Banerjee, R. H2S biogenesis by human cystathionine gamma-lyase leads to the novel sulfur metabolites lanthionine and homolanthionine and is responsive to the grade of hyperhomocysteinemia. J. Biol. Chem. 2009, 284, 11601-11612. [CrossRef] [PubMed]

38. Singh, S.; Padovani, D.; Leslie, R.A.; Chiku, T.; Banerjee, R. Relative contributions of cystathionine beta-synthase and gamma-cystathionase to $\mathrm{H} 2 \mathrm{~S}$ biogenesis via alternative trans-sulfuration reactions. J. Biol. Chem. 2009, 284, 22457-22466. [CrossRef]

39. DeLeon, E.R.; Gao, Y.; Huang, E.; Olson, K.R. Garlic oil polysulfides: H2S- and O2-independent prooxidants in buffer and antioxidants in cells. Am. J. Physiol. Regul. Integr. Comp. Physiol. 2016, 310, R1212-R1225. [CrossRef] [PubMed]

40. Martelli, A.; Testai, L.; Citi, V.; Marino, A.; Pugliesi, I.; Barresi, E.; Nesi, G.; Rapposelli, S.; Taliani, S.; Settimo, F.; et al. Arylthioamides as H2S Donors:1-Cysteine-Activated Releasing Properties and Vascular Effects in Vitro and in Vivo. ACS Med. Chem. Lett. 2013, 4, 904-908. [CrossRef] [PubMed] 
41. Barresi, E.; Nesi, G.; Citi, V.; Piragine, E.; Piano, I.; Taliani, S.; Settimo, F.; Rapposelli, S.; Testai, L.; Breschi, M.; et al. Iminothioethers as Hydrogen Sulfide Donors: From the Gasotransmitter Release to the Vascular Effects. J. Med. Chem. 2017, 60, 7512-7523. [CrossRef] [PubMed]

42. Ida, T.; Sawa, T.; Ihara, H.; Tsuchiya, Y.; Watanabe, Y.; Kumagai, Y.; Suematsu, M.; Motohashi, H.; Fujii, S.; Matsunaga, T.; et al. Reactive cysteine persulfides and S-polythiolation regulate oxidative stress and redox signaling. Proc. Natl. Acad. Sci. USA 2014, 111, 7606-7611. [CrossRef] [PubMed]

43. Basic, A.; Blomqvist, S.; Carlén, A.; Dahlén, G. Estimation of bacterial hydrogen sulfide production in vitro. J. Oral Microbiol. 2015, 7, 28166. [CrossRef]

44. SulfoBiotics-SSP4 I Dojindo. Available online: https://www.dojindo.eu.com/store/p/864-SulfoBiotics-SSP4. aspx (accessed on 7 November 2018).

45. Sitdikova, G.F.; Fuchs, R.; Kainz, V.; Weiger, T.M.; Hermann, A. Phosphorylation of BK channels modulates the sensitivity to hydrogen sulfide (H2S). Front. Physiol. 2014, 5, 431. [CrossRef]

46. Sakaguchi, M.; Marutani, E.; Shin, H.-S.; Chen, W.; Hanaoka, K.; Xian, M.; Ichinose, F. Sodium thiosulfate attenuates acute lung injury in mice. Anesthesiology 2014, 121, 1248-1257. [CrossRef]

47. Olson, K.R.; Gao, Y.; DeLeon, E.R.; Arif, M.; Arif, F.; Arora, N.; Straub, K.D. Catalase as a sulfide-sulfur oxido-reductase: An ancient (and modern?) regulator of reactive sulfur species (RSS). Redox Biol. 2017, 12, 325-339. [CrossRef]

48. Olson, K.R.; Gao, Y.; Arif, F.; Arora, K.; Patel, S.; DeLeon, E.; Straub, K.D. Fluorescence quenching by metal centered porphyrins and poryphyrin enzymes. Am. J. Physiol. Regul. Integr. Comp. Physiol. 2017, 313, R340-R346. [CrossRef] [PubMed]

49. Olson, K.R.; Gao, Y.; Arif, F.; Arora, K.; Patel, S.; DeLeon, E.R.; Sutton, T.R.; Feelisch, M.; Cortese-Krott, M.M.; Straub, K.D. Metabolism of hydrogen sulfide (HS) and Production of Reactive Sulfur Species (RSS) by superoxide dismutase. Redox Biol. 2018, 15, 74-85. [CrossRef] [PubMed]

50. Marutani, E.; Sakaguchi, M.; Chen, W.; Sasakura, K.; Liu, J.; Xian, M.; Hanaoka, K.; Nagano, T.; Ichinose, F. Cytoprotective effects of hydrogen sulfide-releasing-methyl-D-aspartate receptor antagonists are mediated by intracellular sulfane sulfur. Medchemcomm 2014, 5, 1577-1583. [CrossRef]

51. Pitchaimani, A.; Nguyen, T.D.T.; Koirala, M.; Zhang, Y.; Aryal, S. Impact of cell adhesion and migration on nanoparticle uptake and cellular toxicity. Toxicol. In Vitro 2017, 43, 29-39. [CrossRef] [PubMed] 